\title{
DEVELOPMENT AND VALIDATION OF ULTRAVIOLET-SPECTROPHOTOMETRIC METHOD FOR DETERMINATION OF FEBUXOSTAT FOR CONDUCTING IN-VITRO QUALITY CONTROL TESTS IN BULK AND PHARMACEUTICAL DOSAGE FORMS
}

\author{
JASPREET KAUR ${ }^{1,2 *}$, DALJIT KAUR ${ }^{2}$, SUKHMEET SINGH ${ }^{2}$ \\ ${ }^{1}$ Department of Pharmaceutical Sciences, I. K. Gujral Punjab Technical University, Kapurthala - 144 603, Punjab India. ${ }^{2}$ Department of \\ Pharmaceutical Sciences, Rayat-Bahra Institute of Pharmacy, Hoshiarpur - 146 001, Punjab, India. Email: jaspreet.meehnian@gmail.com
}

Received: 28 February 2018, Revised and Accepted: 3 May 2018

ABSTRACT

Objective: A simple, accurate, and selective ultraviolet-spectrophotometric method has been developed for the estimation of febuxostat in the bulk and pharmaceutical dosage forms.

Method: The method was developed and validated according to International Conference on Harmonization (ICH Q2 R1) guidelines. The developed method was validated statistically with respect to linearity, range, precision, accuracy, ruggedness, limit of detection (LOD), limit of quantitation (LOQ), and recovery. Specificity of the method was demonstrated by applying different stressed conditions to drug samples such as acid hydrolysis, alkaline hydrolysis, oxidative, photolytic, and thermal degradation.

Results: The study was conducted using phosphate buffer $\mathrm{pH} 6.8$ and $\lambda_{\max }$ was found to be $312 \mathrm{~nm}$. Standard plot having a concentration range of $1-10 \mu \mathrm{g} / \mathrm{ml}$ showed a good linear relationship with $\mathrm{R}^{2}=0.999$. The LOD and LOQ were found to be $0.118 \mu \mathrm{g} / \mathrm{ml}$ and $0.595 \mu \mathrm{g} / \mathrm{ml}$, respectively. Recovery and percentage relative standard deviations were found to be $100.157 \pm 0.332 \%$ and $<2 \%$, respectively.

Conclusion: Proposed method was successfully applicable to the pharmaceutical formulations containing febuxostat. Thus, the developed method is found to be simple, sensitive, accurate, precise, reproducible, and economical for the determination of febuxostat in pharmaceutical dosage forms.

Keywords: Ultraviolet-spectrophotometric, Febuxostat, Validation.

(C) 2018 The Authors. Published by Innovare Academic Sciences Pvt Ltd. This is an open access article under the CC BY license (http://creativecommons. org/licenses/by/4. 0/) DOI: http://dx.doi.org/10.22159/ajpcr.2018.v11i9.25550

\section{INTRODUCTION}

Febuxostat is a novel non-purine selective xanthine oxidase inhibitor, chemically it is 2-[3-cyano-4-(2-methlypropoxy)phenyl]-4methlythiazole-5-carboxylic acid. It is approved in the Indian market by the year 2009 by Central Drugs Standard Control Organization [1]. It is available in the dose of 80 or $120 \mathrm{mg}$. It has been found as highly protein bound drug (98\%) mainly at diazepam binding site. It is highly effective in the long-term management of hyperuricemia in patients with gout and chronic tophaceous gout [2]. It has a molecular weight of $319.68 \mathrm{~g} / \mathrm{mol}$ with an empirical formula (Fig. 1) of $\mathrm{C}_{16} \mathrm{H}_{16} \mathrm{~N}_{2} \mathrm{O}_{3} \mathrm{~S}$. It has crystalline and nonhygroscopic nature. It has poor solubility profile in water but freely soluble in dimethylformamide, soluble in dimethylsulfoxide, sparingly soluble in ethanol, and slightly soluble in methanol and acetonitrile [3]. It gets metabolized by uridine diphosphate glucuronosyltransferase enzymes to its acyl glucuronide metabolite and lesser extent to its oxidative metabolite such as 67M-1, 67M-2, and 67M-4 through cytochrome P450 enzymes. It has been recommended as a potential alternative to allopurinol in those patients not tolerating or having an inadequate reduction in the level of serum uric acid when treated with allopurinol [4].

\section{METHODS}

\section{Chemicals and reagents}

Standard sample of febuxostat was a generous gift sample from Ami Lifesciences, Gujarat, India. Guar gum and Carbopol 940 were obtained from CDH Pvt., Ltd. The marketed tablets of febuxostat (Myfeb-80) containing $80 \mathrm{mg}$ of febuxostat, manufactured by Stevels Pharma Ltd., India, were purchased from the market. All other chemicals used were of analytical grade.

\section{Instrumentation}

A double beam Systronics ultraviolet (UV)-visible spectrophotometer, model UV-2201 (India) having a spectral bandwidth of $1 \mathrm{~nm}$, wavelength accuracy of $\pm 0.5 \mathrm{~nm}$, and a pair of $1 \mathrm{~cm}$ quartz cells were used to measure the absorbance of the resulting solutions.

\section{Preparation of standard stock solution}

Accurately weighed the quantity of $10 \mathrm{mg}$ febuxostat was transferred into $10 \mathrm{ml}$ volumetric flask, and then $1 \mathrm{ml}$ methanol was added as a cosolvent. The volume was adjusted up to the mark with phosphate buffer $\mathrm{pH}$ 6.8. The prepared solution was found to be a clear solution having the strength $1000 \mu \mathrm{g} / \mathrm{ml}$.

\section{Preparation of sample stock solution}

$1 \mathrm{ml}$ stock solution was taken in the $100 \mathrm{ml}$ volumetric flask and then diluted up to the mark with phosphate buffer $\mathrm{pH} 6.8$ to get the sample stock solution having the strength $10 \mu \mathrm{g} / \mathrm{ml}$. Then, further dilutions were made from 1 to $10 \mu \mathrm{g} / \mathrm{ml}$.

Determination of $\lambda_{\text {max }}$

The standard solution of febuxostat $(10 \mu \mathrm{g} / \mathrm{ml})$ was scanned in the wavelength region of $200-400 \mathrm{~nm}$.

\section{Validation [5-14]}

In the method, development validation plays an important role in analytical determination. Validation covers six main parameters for method development such as linearity and range, precision and accuracy, limit of detection (LOD), limit of quantitation (LOQ), recovery, and ruggedness.

\section{Linearity and range}

To determine the linearity, Three independent levels of calibration curve were analyzed in the range of $1-10 \mu \mathrm{g} / \mathrm{ml}$. The absorbance of each solution was recorded at $312 \mathrm{~nm}$ against phosphate buffer $\mathrm{pH} 6.8$. The calibration curve was plotted, and the correlation coefficient and regression line equation for febuxostat were determined. 


\section{Precision}

Determination of intraday precision was done by analyzing febuxostat $(1-10 \mu \mathrm{g} / \mathrm{ml})$ at 3 different time points of the same day, and the determination of the interday precision was done by analyzing febuxostat (1-10 $\mu \mathrm{g} / \mathrm{ml})$ at 3 different time points on different days.

\section{Accuracy}

The accuracy of the method was determined by percentage recovery experiments performed at three different levels such as 50\%, 100\%, and $150 \%$. A known amount of standard febuxostat solutions were added to the pre-analyzed sample solutions. Absorbance was recorded, and percentage recovery was estimated using the calculated amount of drug in the following formula.

$$
\% \text { Recovery }=\mathrm{A}-\mathrm{B} / \mathrm{C} * 100
$$

Where, A represents total amount of drug estimated $\mathrm{B}$ represents amount of drug found on pre-analyzed basis $\mathrm{C}$ represents amount of pure drug added.

\section{Ruggedness}

The ruggedness of the purposed method was evaluated by applying the same developed procedure to assay $10 \mu \mathrm{g} / \mathrm{ml}$ of febuxostat using the same instrument by two different analysts at different days under the same conditions. The obtained results were evaluated for the reproducibility.

\section{LOD and LOQ [15]}

LOD and LOQ were calculated using following formula:

$$
\mathrm{LOD}=3.3 * \sigma / \mathrm{S} \text { and } \mathrm{LOQ}=10 * \sigma / \mathrm{S}
$$

Where, $\sigma$ is the standard deviation of $y$-intercepts of regression lines $\mathrm{S}$ is the slope of the calibration curve.

\section{Forced degradation study (stressed conditions) [16]}

A $2 \mathrm{ml}$ of the standard stock solution $(1000 \mu \mathrm{g} / \mathrm{ml})$ of Febuxostat was taken as four replicates in four different volumetric flasks of $100 \mathrm{ml}$ and mixed with $10 \mathrm{ml}$ of following (1-3) solutions. Then, all the flasks were set aside for $1 \mathrm{~h}$ at room temperature. The solution was diluted up to mark with double distilled water

1. $0.1 \mathrm{~N} \mathrm{HCl}$ for acid hydrolysis.

2. $0.1 \mathrm{~N} \mathrm{NaOH}$ for alkaline hydrolysis.

3. $5 \% \mathrm{H}_{2} \mathrm{O}_{2}$ for oxidative degradation.

4. For photolytic degradation, a solution of drug $(10 \mu \mathrm{g} / \mathrm{ml})$ was exposed to UV radiation of wavelength $254 \mathrm{~nm}$ and of 1.4 flux intensity for $24 \mathrm{~h}$ in a UV chamber.

5. For thermal degradation, solid pure drug was kept in an oven at $100^{\circ} \mathrm{C}$ for $24 \mathrm{~h}$. After cooling to room temperature, $10 \mu \mathrm{g} / \mathrm{ml}$ solution was prepared.

The absorbance of all the solutions from acid hydrolysis, alkaline hydrolysis, oxidative degradation, photolytic degradation, and thermal degradation was measured at $312 \mathrm{~nm}$ against respective solvent as blank in each case

\section{Formulation of febuxostat loaded hydrogel $[17,18]$}

The hydrogel was prepared using hydrophilic polymer guar gum $(0.75 \%)$ and Carbopol $940(1 \%)$

Carbopol 940 is water soluble while guar gum produces colloidal dispersion with water. Dispersion of polymers was made using magnetic stirrer (500 rpm). For complete swelling of both polymers, dispersions were kept in the dark for 24 h. Dispersing Carbopol 940 in distilled water was followed by slow addition of guar gum dispersion under continuous stirring. Aqueous drug solution was added to the polymeric dispersion after addition of $0.1 \mathrm{~N}$ sodium hydroxide solution which acts as a cross-linking agent. Finally, the remaining distilled water was added to obtain a homogeneous dispersion of gel under magnetic stirring
Comparative study of calibration curve with standard plot or analysis of marketed formulation (Myfeb-80) and prepared hydrogel by UV-spectrophotometric method

Ten marketed tablets of febuxostat (Myfeb-80) containing $80 \mathrm{mg}$ drug per tablet were taken in pestle and mortar. Weighed amount of the powder equivalent to $10 \mathrm{mg}$ of febuxostat was transferred into the $10 \mathrm{ml}$ volumetric flask, $1 \mathrm{ml}$ methanol was added as a cosolvent and finally, diluted up to the mark with phosphate buffer $\mathrm{pH} 6.8$ to produce a solution of $10 \mathrm{ml}$. The prepared solution was found to be a clear having the strength $1000 \mu \mathrm{g} / \mathrm{ml}$, which was a stock solution. From this stock solution, $1 \mathrm{ml}$ of solution was taken and transferred to $100 \mathrm{ml}$ volumetric flask and further diluted with $\mathrm{pH} 6.8$ phosphate buffer to get a concentration of $10 \mu \mathrm{g} / \mathrm{ml}$. From this solution, dilutions were prepared in the range $1-10 \mu \mathrm{g} / \mathrm{ml}$ and were analyzed at $312 \mathrm{~nm}$.

Assay of marketed formulation Myfeb-80 by developed method [19] Ten marketed tablets of febuxostat (Myfeb-80) were taken and average weight was determined. Then, the mixture was ground and mixed well. The powder of the sample equivalent to $10 \mathrm{mg}$ of febuxostat was accurately weighed (22.62 mg powder) and transferred into $10 \mathrm{ml}$ volumetric flask. Then, $1 \mathrm{ml}$ of methanol was added, and final volume was adjusted using phosphate buffer $\mathrm{pH} 6.8$ sonicated for 5 min to get a clear solution of strength $1000 \mu \mathrm{g} / \mathrm{ml}$. Then, the content of the flask was filtered using Whatman filter of pore size $0.45 \mu$. From this stock solution, $1 \mathrm{ml}$ of solution was taken and transferred to $100 \mathrm{ml}$ volumetric flask by adjusting the volume up to $100 \mathrm{ml}$, using phosphate buffer $\mathrm{pH} 6.8$ which gives a solution of strength $10 \mu \mathrm{g} / \mathrm{ml}$. This solution was prepared 5 times, and the absorbance of each solution was determined at $312 \mathrm{~nm}$, and the concentration of drug present in sample solution was calculated; hence, drug present per tablet was also calculated.

\section{Assay of prepared hydrogel [20]}

$50 \mathrm{mg}$ of prepared gel (equivalent to $1.0 \mathrm{mg}$ of febuxostat) was weighed accurately and it was dissolved in $100 \mathrm{ml}$ of phosphate buffer of pH 6.8 . The conical flask containing gel was shaken for $2 \mathrm{~h}$ on mechanical shaker to get complete solubility of febuxostat.

The resulting solution is filtered through Whatman filter paper; the febuxostat content was analyzed spectrophotometrically at $312 \mathrm{~nm}$ using a UV spectrophotometer (Systronics, India). The measurement was carried out in triplicate, and the average febuxostat content in the topical gel was calculated.

\section{RESULTS}

Determination of $\lambda_{\max }$

When a standard solution having concentration $10 \mu \mathrm{g} / \mathrm{ml}$ was scanned, the $\lambda_{\text {max }}$ was found to be $312 \mathrm{~nm}$ as shown in Fig. 2 .

\section{Linearity and range}

The linearity of febuxostat was found to be in the range of 1-10 $\mu \mathrm{g} /$ $\mathrm{ml}$ with correlation coefficient 0.999 . Standard plot data and curve are given in Table 1 and Fig. 3.

Table 1: Standard plot of pure drug (Febuxostat)

\begin{tabular}{lll}
\hline Sr. no. & Concentration $(\mu \mathrm{g} / \mathrm{ml})$ & Absorbance* ${ }^{*} \mathrm{SD}$ \\
\hline 1 & 1 & $0.120 \pm 0.011$ \\
2 & 2 & $0.214 \pm 0.022$ \\
3 & 3 & $0.282 \pm 0.019$ \\
4 & 4 & $0.379 \pm 0.019$ \\
5 & 5 & $0.465 \pm 0.014$ \\
6 & 6 & $0.541 \pm 0.017$ \\
7 & 7 & $0.625 \pm 0.012$ \\
8 & 8 & $0.726 \pm 0.017$ \\
9 & 9 & $0.808 \pm 0.016$ \\
10 & 10 & $0.879 \pm 0.026$ \\
\hline
\end{tabular}

*Average of three observations. SD: Standard deviation 
The standard plot was successfully prepared, the equation of straight line give regression coefficient value near to one which confirms data fits into the equation of straight line.

\section{Precision}

\section{Intraday precision}

The percentage relative standard deviations (RSD) was found to be in the range of $0.126-0.251 \%$ ( Table 2 ) which is $<1$ which confirms the reliability of the method.

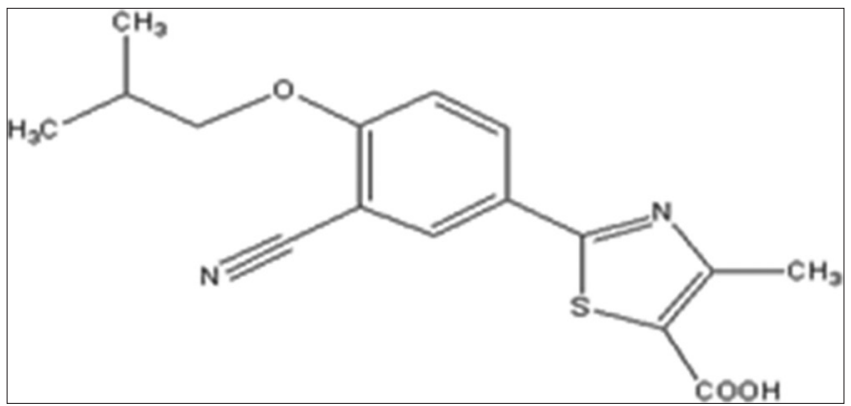

Fig. 1: Structure of febuxostat

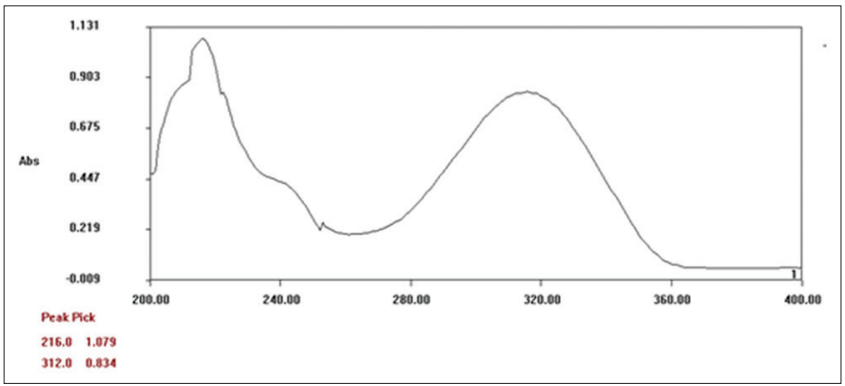

Fig. 2: Ultraviolet spectrum of pure drug (Febuxostat)

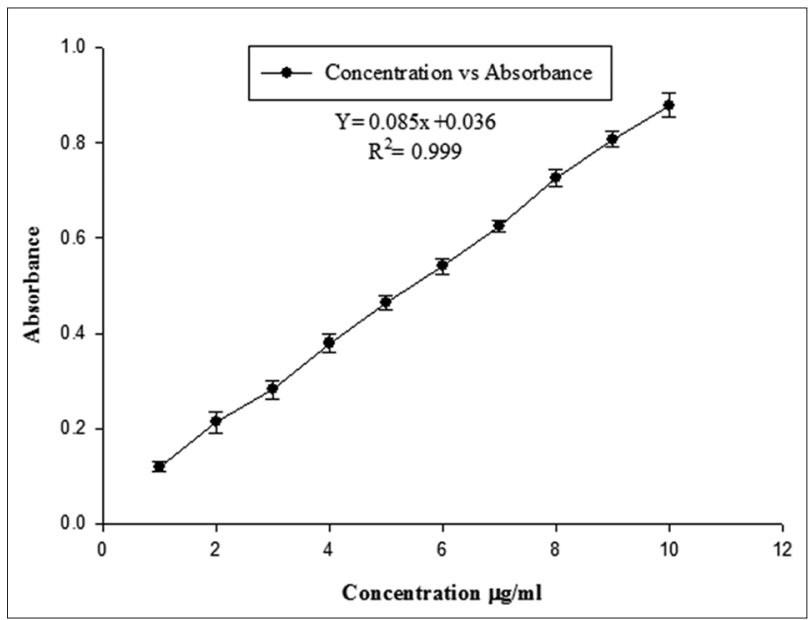

Fig. 3: Standard plot of pure drug (Febuxostat)

\section{Interday precision}

The percentage RSD was found to be in the range of 0.135-0.591\% (Table 3 ) which is $<1$ which strongly confirms the reliability of the method.

\section{Accuracy}

The accuracy of the method was checked by the recovery studies at three different levels, i.e., $50 \%, 100 \%$, and $150 \%$. The mean of the recovery for febuxostat was found to be $100.157 \pm 0.332 \%$. The results obtained were shown in Table 4.

\section{Ruggedness}

The obtained results were found to be reproducible (Table 5) since there was no significant difference between analysts. Thus, the proposed method was considered to be rugged.

\section{LOD and LOQ}

The sensitivity of the method was assessed by determining the LOD and LOQ. The LOD and LOQ for Febuxostat were found to be $0.118 \mu \mathrm{g} / \mathrm{ml}$ and $0.595 \mu \mathrm{g} / \mathrm{ml}$, respectively.

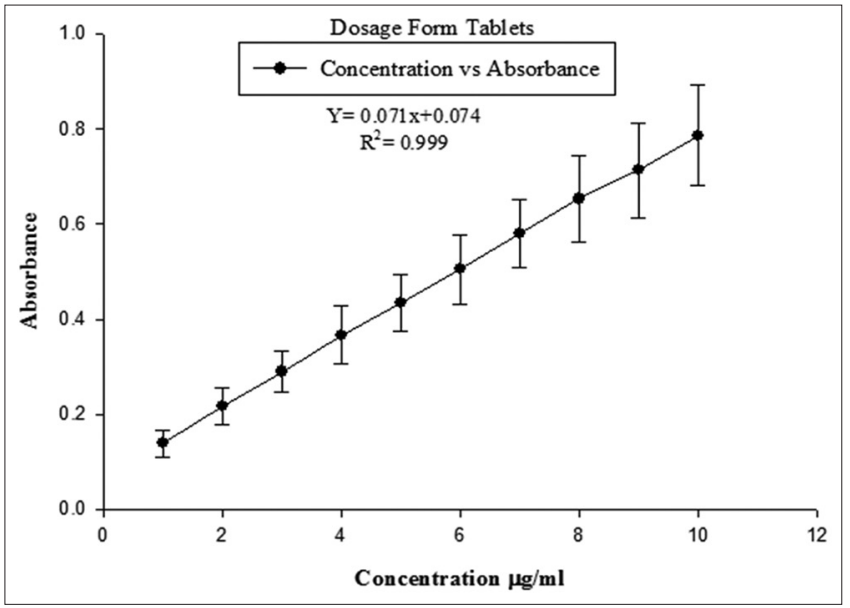

Fig. 4: Calibration curve of febuxostat drug-containing tablet by simple ultraviolet-spectrophotometer

Table 2: Results of intraday precision

\begin{tabular}{llll}
\hline Concentration $(\boldsymbol{\mu g} / \mathbf{m l})$ & Absorbance* $^{*}$ & SD & \%RSD \\
\hline 2 & 0.223 & 0.003 & 0.142 \\
4 & 0.377 & 0.003 & 0.126 \\
6 & 0.540 & 0.005 & 0.251 \\
\hline
\end{tabular}

*Average of three observations. SD: Standard deviation, RSD: Relative standard deviations

Table 3: Results of interday precision

\begin{tabular}{llll}
\hline Concentration $(\boldsymbol{\mu g} / \mathbf{m l})$ & Absorbance* & SD & \%RSD \\
\hline 2 & 0.238 & 0.003 & 0.135 \\
4 & 0.397 & 0.014 & 0.591 \\
6 & 0.543 & 0.005 & 0.192 \\
\hline * Average of three observations. SD: Standard deviation
\end{tabular}

(a) of three observations. SD: Standard deviation, RSD: Relative standard deviations

Table 4: Results of recovery studies

\begin{tabular}{lllll}
\hline Amount of sample $^{*}(\boldsymbol{\mu g} / \mathbf{m l})$ & Amount of drug added $(\boldsymbol{\mu g} / \mathbf{m l})$ & \% of spiked sample & Amount recovered $(\boldsymbol{\mu g} / \mathbf{m l})$ & \% Recovery \\
\hline 2 & 1 & $50 \%$ & 3.245 & $101.11 \pm 0.398$ \\
2 & 2 & $100 \%$ & 4.271 & $98.876 \pm 0.246$ \\
2 & 3 & $150 \%$ & 5.357 & $100.484 \pm 0.352$ \\
\hline
\end{tabular}

*Average of three observations 
Table 5: Ruggedness data at $10 \mu \mathrm{g} / \mathrm{ml}$ of febuxostat by two analysts at different days

\begin{tabular}{lll}
\hline Test concentration $(\boldsymbol{\mu g} / \mathrm{ml}) * *$ & Analyst-I & Analyst-II \\
\hline $10 \mu \mathrm{g} / \mathrm{ml}$ & 0.887 & 0.885 \\
$\mathrm{SD}$ & 0.085 & 0.091 \\
$\% \mathrm{RSD}$ & 0.838 & 0.897 \\
\hline
\end{tabular}

**Average of five observations. SD: Standard deviation, RSD: Relative standard deviations

Table 6: Results of the drug under stressed conditions

\begin{tabular}{lllll}
\hline Parameter studied & Concentration taken* $(\boldsymbol{\mu g} / \mathbf{m l})$ & Concentration obtained* $(\boldsymbol{\mu g} / \mathbf{m l})$ & \% Drug degradation* & \% Drug recovered* \\
\hline Acid hydrolysis & 10 & 8.93 & 10.7 & 9.2 \\
Alkaline hydrolysis & 10 & 9.08 & 3.7 & 90.8 \\
Oxidative degradation & 10 & 9.63 & 10.8 & 96.3 \\
Photolytic degradation & 10 & 8.92 & 89.2 \\
Thermal degradation & 10 & 8.61 & 13.9 \\
\hline
\end{tabular}

*Average of three observations

Table 7: Calibration data of febuxostat tablet by simple UV-Spectrophotometer

\begin{tabular}{lll}
\hline Sr. no. & Concentration $(\boldsymbol{\mu g} / \mathbf{m l})$ & Absorbance ${ }^{*}$ SD \\
\hline 1 & 1 & $0.139 \pm 0.028$ \\
2 & 2 & $0.218 \pm 0.039$ \\
3 & 3 & $0.290 \pm 0.044$ \\
4 & 4 & $0.366 \pm 0.061$ \\
5 & 5 & $0.435 \pm 0.059$ \\
6 & 6 & $0.506 \pm 0.073$ \\
7 & 7 & $0.580 \pm 0.072$ \\
8 & 8 & $0.654 \pm 0.091$ \\
9 & 9 & $0.713 \pm 0.100$ \\
10 & 10 & $0.786 \pm 0.106$ \\
\hline$*$
\end{tabular}

*Average of three observations, UV: Ultraviolet, SD: Standard deviation

\section{Forced degradation study}

From the result given in Table 6, it was found that there were no significant changes in absorbance after performing acid hydrolysis, alkaline hydrolysis, photolytic degradation, and thermal degradation.

Analysis of marketed formulation (Myfeb) by UVspectrophotometric method

The linearity of the calibration data showed (Table 7) that the proposed method can be successfully applied to the pharmaceutical dosage form without any interference from common excipients. As the drug was same as that of the standard plot so same concentrations were reproduced (Fig. 4), and values were fit into the equation of a straight line, the values were successfully obtained.

Assay of pharmaceutical formulations containing drug febuxostat Validated UV-spectrophotometric method was applied to estimate the amount of drug present in both marketed (Myfeb-80 tablets) and prepared formulation (Hydrogel), obtained results were shown in Tables 8 and 9.

In both prepared and marketed formulations, we were successful to estimate drug accurately that was claimed in the formulations.

\section{Statistical analysis of standard plot and calibration curve}

As we considered null hypothesis that is no significant difference in obtained absorbance of standard plot and calibration plot, $\mathrm{Ha}$ is one-sided, so we had applied one-tail t-test for determining the rejection region at $5 \%$ level, which comes as 1.833 under the table of $\mathrm{t}$-distribution for $9^{\circ}$ of freedom. The calculated value of $\mathrm{t}$ comes out to be 0.201 , which is in the acceptance region thus we concluded that difference between two sample data is insignificant.

All the validation parameters are summarized in Table 10, shows that the proposed UV spectrophotometric method is found to be accurate, rapid, simple, precise, selective, reproducible, and economical.

\section{DISCUSSION}

The standard plot was successfully prepared thrice with a very low error which indicates that method is quite accurate as there is precision in method followed and the readings were fit to the line of best fit in the equation of the straight line with high $\mathrm{R}^{2}$ value. All other validation parameters were also in reasonable range confirming the followed method of estimation is accurate, precise, and reproducible. To confirm the reproducibility of the standard curve, same drug concentrations were prepared from marketed formulations in a repeated manner. The observations were obtained. Thereafter, "t-test" was applied considering the null hypothesis. After calculation of " $t$ " value, it was confirmed that there was not a significant difference in observation of prepared standard curve with that of the calibration curve. However, from forced degradation study, it is also revealed that drug is quite stable at diverse conditions.

\section{CONCLUSION}

From above study, it has been concluded that the developed method for the determination of febuxostat in pharmaceutical formulations was found to be simple, sensitive, accurate, precise, reproducible, and economical. The purity of the drug peak was assessed by analyzing the spectra. High $R^{2}$ value in linearity and percentage $R S D<2$ indicate good results. The interday precision at three level of concentration on 3 different days also provides evidence about the ruggedness of the analytical method due to the low value of percentage RSD. Thus, the method was found to be specific. The lowest value of LOD obtained by proposed method proved that the method followed was the most sensitive method. Small but deliberate changes do not affect the method which indicates that the proposed method was found to be robust. Percentage RSD of the pharmaceutical formulation was found to be $0.0725 \%$ which showed that there was no interference from the excipients used in the formulation which indicates the accuracy and reliability of the method. To ensure the specificity of the developed method, it was calibrated with the market formulation of febuxostat, two evaluated parameters that were calibration and assay ensures that the developed method can be used for routine analysis for estimation of febuxostat in bulk and pharmaceutical dosage form.

\section{ACKNOWLEDGMENT}

The authors are thankful to Ami Lifesciences, Gujarat, for providing the gift sample of pure drug febuxostat. Authors are also grateful to RayatBahra Institute of Pharmacy, Hoshiarpur, for providing facilities and great facilitation to accomplish this research work.

\section{AUTHOR'S CONTRIBUTION}

Designing of experiment, forced degradation study, hydrogel preparation and its analysis, comparative study, and statistical analysis was carried out by Jaspreet Kaur. Whereas, Daljit Kaur had arranged gift sample of drug and other chemicals required to carry out the study. 
Table 8: Assay of pharmaceutical formulations Myfeb-80

\begin{tabular}{lllll}
\hline Formulation & Label Claimed* $(\mathbf{m g})$ & Amount recovered $\mathbf{( m g )}$ & \% Drug recovered & \% RSD \\
\hline Myfeb-80 (tablet) & 80 & $79.890 \pm 0.024$ & $99.862 \pm 0.03$ & 0.0725 \\
\hline${ }^{*}$ Average of three observations. RSD: Relative standard deviations & & &
\end{tabular}

Table 9: Assay of prepared hydrogel

\begin{tabular}{lllll}
\hline Formulation & Amount taken equivalent to $(\boldsymbol{\mu g})$ & Amount recovered $(\boldsymbol{\mu g})$ & \% Drug recovered & \% RSD \\
\hline Hydrogel & 10 & $9.705 \pm 0.038$ & $97.050 \pm 0.03$ & 0.0973 \\
\hline
\end{tabular}

*Average of three observations. RSD: Relative standard deviations

Table 10: Summary of the validation parameters of UV-spectrophotometry

\begin{tabular}{lll}
\hline Sr. No. & Parameter & Result \\
\hline 1 & $\lambda_{\text {max }}(\mathrm{nm})$ & 312 \\
2 & Beer's law limit $(\mu \mathrm{g} / \mathrm{ml})$ & $1-10$ \\
3 & Regression equation & $0.085 \mathrm{x}+0.036$ \\
4 & Slope & 0.085 \\
5 & Intercept & 0.036 \\
6 & Correlation coefficient $\left(\mathrm{R}^{2}\right)$ & 0.999 \\
7 & Precision $(\% \mathrm{RSD})$ & \\
& Intraday & $0.126-0.251 \%$ \\
& Interday & $0.135-0.591 \%$ \\
8 & \% Recovery & $100.157 \pm 0.332 \%$ \\
9 & LOD $(\mu \mathrm{m} / \mathrm{ml})$ & 0.118 \\
10 & LOQ $(\mu \mathrm{m} / \mathrm{ml})$ & 0.595 \\
11 & Assay & \\
& Myfeb-80 tablets & $99.862 \%$ \\
& Hydrogel & $97.050 \%$ \\
\hline
\end{tabular}

UV: Ultraviolet, LOD: Limit of detection, LOQ: Limit of quantitation

Validation study parameters were carried by Daljit and Sukhmeet Singh Kamal. The manuscript had been written by first two authors.

\section{CONFLICTS OF INTEREST}

Authors have no conflicts of interest.

\section{REFERENCES}

1. Panda BK, Parge V, Singh P, Patel CS, Marne SR. Febuxostat, a nonpurine selective xanthine oxidase inhibitor in the management of hyperuricemia and chronic gout: A systematic review. J Adv Sci Res 2012;3:3-11.

2. Shinde SS, Deshmukh AS, Nagadkar PP, Tiwari KJ. Study of febuxostat for the management of hyperuricemia in gout. Int $\mathrm{J}$ Pharm Pharm Res 2015;4:279-88.

3. Pandey A, Chaturvedi M, Prakash H, Meena D. Febuxostat-a new treatment for hyperuricaemia in gout-a review article. Natl J Physiol Pharm Pharmacol 2012;2:23-8.

4. Bisht M, Bist SS. Febuxostat: A novel agent for management of hyperuricemia in gout. Indian J Pharm Sci 2011;73:597-600.

5. Raviteja, Naik NS, Gayathri, Zahera F. Development and validation of UV spectrophotometric method of febuxostat in bulk and tablet formulations. Int J Chem Pharm Sci 2013;1:337-41.

6. Spandana R, Latha PE, Susmitha J. Method development and validation of spectrophotometric method for the estimation of febuxostat in pure and tablet dosage form. Int J Pharm Pharm Res 2015;3:38-46.
7. Sudhir MS, Mohan PM, Nadh RV. Simple and validated ultraviolet spectrophotometric method for the estimation of febuxostat in bulk and pharmaceutical dosage forms. Orient J Chem 2013;29:235-40.

8. Sowjanya G, Srinivas L, Rajasri A. New validated UV spectrophotometric methods for the determination of febuxostat in bulk and formulation. Cibtech J Pharm Sci 2014;3:7-13.

9. Bagga P, Salman M, Siddiqui HH, Ansari AM, Mehmood T, Singh K. A simple UV spectrophotometric method for the determination of Febuxostat in bulk and pharmaceutical formulations. Int J Pharm Sci Res 2011;2:2655-9.

10. Sheth M, Joshi S, Patel M. Development and application of difference spectrophotometric method for the determination of febuxostat in tablets. Int J Pharm Sci Res 2012;3:1621-4.

11. Musirike MR, Reddy HK, Mallu UR. Development and validation of reverse phase-ultra performance liquid chromatographic method for estimation of related substances in Febuxostat drug substance. Pharm Anal Acta 2015;6:1-10

12. Ding X, Zhang Q, Wang Z, Lin G. Development and validation of liquid chromatography-mass spectrometry method for determination of febuxostat in rat plasma and its application. Lat Am J Pharm 2012;31:321-5.

13. Prasad AR, Ratna JV. Development and validation of a simple UVspectrophotometric method for the determination of ciprofloxacin $\mathrm{HCl}$ present in taste masked drug resin complex. Int J App Pharm 2018;10 Suppl 3:37-41.

14. Zadbuke N, Shahi S, Jadhav A, Borde S. Development and validation of UV-Visible Spectroscopic method for estimation of carbamazepine in bulk and tablet dosage. Int J Pharm Pharm Sci 2015;8 Suppl 2:234-8.

15. Wamorkar V, Manjunath SY, Varma MM. Development and validation of UV spectroscopic method for determination of metoclopramide hydrochloride in bulk and tablet formulation. Int J Pharm Pharm Sci 2011;3 Suppl 3:171-4

16. Ethiraj R, Thiruvengadam E, Sampath VS, Vahid A, Raj J. Development and validation of stability indicating spectroscopic method for content analysis of ceftriaxone sodium in pharmaceuticals Int Sch Res Notices 2014. DOI: $10.1155 / 2014 / 278173$.

17. Monica SA, Gautami J. Design and evaluation of topical hydrogel formulation of diclofenac sodium for improved therapy. Int J Pharm Sci Res 2014:5 Suppl 5:1973-80.

18. Yadav N, Goyal A. A validated Spectrophotometric method for determination of vilazodone hydrochloride in pharmaceutical dosage form. Int J Curr Pharm Res 2016;9 Suppl 1:132-5.

19. Syed MR, Hashmi S, Naik JB. UV Spectrophotometric method development and validation for determination of paroxetine hydrochloride in pharmaceutical dosage form. Int J Pharm Pharm Sci 2010;2 Suppl 2:43-5

20. Swetha $\mathrm{CH}$, Velmurugun $\mathrm{S}$, Raju PN, Reddy GN. Formulation and evaluation of clarithromycin topical gel. Int J Drug Dev Res 2013;5:194-202. 